\title{
Bradycardia, Renal Failure, Atrioventricular- nodal Blocker, Shock, and Hyperkalemia Syndrome Diagnosis and Literature Review
}

\author{
Yasar Sattar ${ }^{1}$, Syeda Beenish Bareeqa ${ }^{2}$, Hiba Rauf $^{3}$, Waqas Ullah ${ }^{4}$, M. Chadi Alraies ${ }^{5}$ \\ 1. Internal Medicine, Icahn School of Medicine at Mount Sinai, New York, USA 2. Internal Medicine, Jinnah Medical and \\ Dental College, Karachi, PAK 3. Internal Medicine, Dow Medical College, Karachi, PAK 4. Internal Medicine, Abington \\ Hospital-Jefferson Health, Abington, USA 5. Cardiology, Detroit Medical Center, Detroit, USA
}

Corresponding author: Yasar Sattar, sattary@nychhc.org

\begin{abstract}
The combination of bradycardia, renal failure, atrioventricular (AV)-nodal blocker medications, shock, and hyperkalemia (BRASH) is a new syndrome that is a consequence of a positive loop of bradycardia due to AVnodal blockers and hyperkalemia secondary to renal insufficiency. We present a case of BRASH syndrome in which the patient on chronic AV-nodal blockers presented with bradycardia, hypotension, underlying kidney dysfunction, and hyperkalemia. The patient was medically managed and discharged upon clinical improvement. The purpose of this report is to highlight the rare cases of BRASH syndrome and improve its management.
\end{abstract}

Categories: Cardiology, Internal Medicine, Nephrology

Keywords: brash syndrome, bradycardia, av nodal blockers, shock, hyperkalemia

\section{Introduction}

Bradycardia, renal failure, atrioventricular (AV)-nodal blocker medications, shock, and hyperkalemia (BRASH) is a recently described syndrome by Josh Farkas in 2016. The syndrome results in severe bradycardia and hypotension due to the synergistic overlap of both AV-nodal blocker and hyperkalemia secondary to underlying renal failure. It can be triggered by risk factors that increase potassium, including fever, sepsis, medications, tumor lysis, renal insufficiency, diabetes, and hypovolemia. The investigations are centered on the complete metabolic panel and electrocardiogram. In cases where the patient presenting with profound bradycardia and shock does not respond to initial treatment, a diagnosis of BRASH syndrome is likely [1].

\section{Case Presentation}

Received 02/05/2020 Review began 02/12/2020 Review ended 02/12/2020 Published 02/13/2020

(๑) Copyright 2020 Sattar et al. This is an open access article distributed under the terms of the Creative Commons Attribution License CC-BY 4.0., which permits unrestricted use, distribution, and reproduction in any medium, provided the original author and source are credited.
A 66-year-old Caucasian woman was brought in by emergency medical services for concerns of severe lightheadedness that had progressed to a near syncope episode the night before. Prior to her arrival, she had expressed concerns of constant mild lightheadedness for one day, which progressed in severity and prompted her transfer to the hospital. Upon her arrival, she continued to have symptoms but denied any loss of consciousness, seizure, vision blackout, sweating, nausea, vomiting, or diarrhea.

Upon her admission, she was observed for vital derangements. Her vital signs showed marked bradycardia with a heart rate of 35 beats/minute, a blood pressure of $87 / 62 \mathrm{mmHg}$ on standing and 90/65 lying down, a temperature of $98.3^{\circ} \mathrm{F}\left(38.8^{\circ} \mathrm{C}\right)$, a respiratory rate of 24 breaths/minute, and an oxygen saturation of $99 \%$ on $4 \mathrm{~L} / \mathrm{min}$ of nasal cannula oxygen. Physical examination showed a well-nourished and afebrile patient in non-acute distress with dry skin and decreased skin turgor. She had a regular sinus rhythm with normal heart sounds on cardiovascular exam. Both lungs were clear on auscultation with normal breath sounds. Her abdomen was soft and non-tender with no positive findings.

Her past medical history was significant for hypertension, hyperlipidemia, diabetes mellitus type 2, coronary artery disease status with post-coronary intervention performed in 2015. She was taking aspirin $81 \mathrm{mg}$ once daily (OD), atorvastatin $40 \mathrm{mg}$ OD, carvedilol $12.5 \mathrm{mg}$ twice daily (BID), clopidogrel $75 \mathrm{mg}$ OD, losartan 25 $\mathrm{mg}$ OD, and metformin-sitagliptin 500-50 mg BID.

Blood work was negative except for high brain natriuretic peptide at $1,620 \mathrm{pg} / \mathrm{mL}$, creatinine $2.21 \mathrm{mg} / \mathrm{dL}$, blood urea nitrogen $34 \mathrm{mg} / \mathrm{dL}$, troponin 0.811 and $1.66 \mathrm{ng} / \mathrm{mL}$, potassium $6.2 \mathrm{mEq} / \mathrm{L}$, and lactate 5.3 $\mathrm{mmol} / \mathrm{L}$. The electrocardiogram (EKG) findings are shown in Figure 1. 


\section{Cureus}

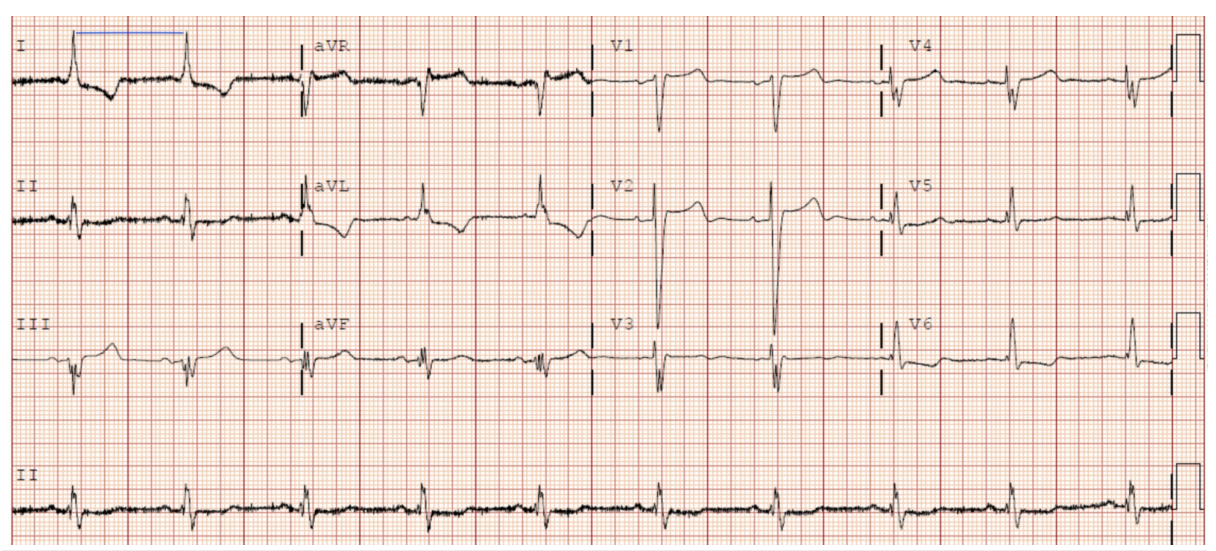

\section{FIGURE 1: Electrocardiogram showing sinus bradycardia with an expected rate of $55 \mathrm{bpm}$}

A constellation of symptomatic bradycardia with EKG findings, a baseline renal dysfunction, hyperkalemia, and an intake of the usual long-term dose of carvedilol suggested a preliminary diagnosis of BRASH. This syndrome precipitated due to a combination of carvedilol and hyperkalemia secondary to acute kidney injury. Treatment was started with an intravenous bolus of $1 \mathrm{~L}$ normal saline, calcium gluconate dose of 0.4 $\mathrm{mEq} / \mathrm{kg}$, and insulin 10 units with $50 \mathrm{~mL} / \mathrm{D} 50$. The patient's heart rate improved to normal with symptomatic resolution after one round of treatment.

\section{Discussion}

This case highlights the importance of BRASH syndrome as a new diagnosis to consider. It is important to understand the physiology of BRASH as the advanced cardiovascular life support (ACLS) bradycardia algorithm generally does not work for BRASH treatment [1]. Hyperkalemia is a "hema-panic call” for physicians but can provide helpful information in some patients with bradycardia, as they have a positive loop of hyperkalemia causing worsening of AV-nodal depression if there is concomitant negative chronotropic drug intake.

Despite numerous cases with similar clinical presentations reported in medical literature, we have observed a paucity in recognition of it as a distinct syndrome. We performed extensive searches in the published medical literature from 2009 through 2019 to identify this anonymous clinical presentation. It was noticed that many clinicians have not clearly mentioned this clinical presentation as BRASH syndrome. Nine cases were identified in seven different studies [2-8]. The age of presentation ranged between 24 and 97 years with the mean age of 72 years. In our case, the presenting patient was 66 years old, which is around the mean age of previously presenting patients. Of the nine patients, female patients were predominant (78\%) while only two were male patients (22\%). The heart rate in patients with bradycardia varies from severe bradycardia (28 bpm) to relatively mild bradycardia (56 bpm) with a median of $33 \mathrm{bpm}$. However, the heart rate was $34 \mathrm{bpm}$ in our patient.

All the patients in discussed cases of BRASH syndrome showed signs of renal failure. AV blockade was observed in seven of nine cases. An experimental study on canines reported that significant EKG changes, suggestive of AV-nodal blockade, are associated with hyperkalemia of $\geqslant 6.3 \mathrm{mEq} / \mathrm{L}[9]$. We have observed a similar correlation in previously reported studies in human patients. Five cases reported serum potassium levels of $\geqslant 6.3 \mathrm{mEq} / \mathrm{L}$ (55.5\%), while four patients had lower potassium levels. All patients with serum potassium levels of $\geqslant 6.3 \mathrm{mEq} / \mathrm{L}$ had concurrent AV blockade, while half of the patients with serum potassium levels of $<6.3 \mathrm{mEq} / \mathrm{L}$ showed no sign of AV blockade on EKG. Cardiac electrical conduction abnormalities are also associated with other metabolic instabilities such as acidosis [10]. Our patient had significant hyperkalemia ( $6.2 \mathrm{mEq} / \mathrm{L})$ with concurrent metabolic acidosis, which explains the EKG changes observed in this case. The details of previously reported anonymous cases on BRASH syndrome are given in Table 1 . 


\section{Cureus}

\begin{tabular}{|c|c|c|c|c|c|c|c|}
\hline Study & $\begin{array}{l}\text { Patient's Age } \\
\text { (Years)/Sex }\end{array}$ & Bradycardia & $\begin{array}{l}\text { Renal } \\
\text { Failure }\end{array}$ & $\begin{array}{l}\text { Atrioventricular } \\
\text { Blockade }\end{array}$ & Shock & Hyperkalemia & Correction \\
\hline $\begin{array}{l}\text { Simmons and } \\
\text { Blazar } 2019 \text { [2] }\end{array}$ & 24 years/male & $\begin{array}{l}40 \\
\text { beats/minute }\end{array}$ & Yes & Yes & No & $7.4 \mathrm{mEq} / \mathrm{L}$ & $\begin{array}{l}\text { Atropine sulfate, calcium } \\
\text { gluconate, pacemaker }\end{array}$ \\
\hline $\begin{array}{l}\text { Ahmad and Tan } \\
2017[3]\end{array}$ & 81 years/temale & $\begin{array}{l}33 \\
\text { beats/minute }\end{array}$ & Yes & Yes & No & $5.8 \mathrm{mEq} / \mathrm{L}$ & Intravenous atropine, isoproterenol \\
\hline $\begin{array}{l}\text { Juvet et al. } 2013 \\
\text { [4] }\end{array}$ & 85 years/female & $\begin{array}{l}33 \\
\text { beats/minute }\end{array}$ & Yes & Yes & Yes & $10.1 \mathrm{mEq} / \mathrm{L}$ & $\begin{array}{l}\text { Insulin, calcium gluconate, } \\
\text { bicarbonates, hemodialysis }\end{array}$ \\
\hline \multirow{2}{*}{$\begin{array}{l}\text { Hegazi et al. } 2012 \\
{[5]}\end{array}$} & 65 years/temale & $\begin{array}{l}48 \\
\text { beats/minute }\end{array}$ & Yes & No & No & $5.6 \mathrm{mEq} / \mathrm{L}$ & Calcıum gluconate, insulin \\
\hline & 57 years/female & $\begin{array}{l}44 \\
\text { beats/minute }\end{array}$ & Yes & No & No & $5.5 \mathrm{mEq} / \mathrm{L}$ & Calcium gluconate \\
\hline \multirow{2}{*}{ Azız et al. 2011 [ } & 97 years/temale & $\begin{array}{l}56 \\
\text { beats/minute }\end{array}$ & Yes & Yes & No & $6.3 \mathrm{mEq} / \mathrm{L}$ & $\begin{array}{l}\text { Calcium chloride, normal saline, } \\
\text { insulin }\end{array}$ \\
\hline & 86 years/female & beats/minute & Yes & Yes & Yes & $5.7 \mathrm{mEq} / \mathrm{L}$ & $\begin{array}{l}\text { Atropine, normal saline, } \\
\text { pacemaker, insulin }\end{array}$ \\
\hline $\begin{array}{l}\text { Erden et al. } 2010 \\
{[7]}\end{array}$ & 76 years/temale & $\begin{array}{l}28 \\
\text { beats/minute }\end{array}$ & Yes & Yes & No & $9.2 \mathrm{mEq} / \mathrm{L}$ & $\begin{array}{l}\text { Temporary percutaneous pacing, } \\
\text { bicarbonate, insulin }\end{array}$ \\
\hline Argulian 2009 [8] & 79 years/male & beats/minute & Yes & Yes & NO & $6.4 \mathrm{mEq} / \mathrm{L}$ & $\begin{array}{l}\text { Calcium gluconate, bicarbonate, } \\
\text { insulin, sodium polystyrene } \\
\text { sulfonate }\end{array}$ \\
\hline
\end{tabular}

TABLE 1: Chart review of studies reporting bradycardia, renal failure, atrioventricular-nodal blocker, shock, and hyperkalemia syndrome from the past decade

The medication history of AV-nodal blockers with the clinical evidence of hyperkalemia is essential to make the diagnosis of BRASH syndrome. In previous studies, the most used AV-nodal blockers that resulted in BRASH syndrome were $\beta$-blockers and calcium-channel blockers. These data are tabulated in Table 2.

\begin{tabular}{|c|c|c|}
\hline Study & Atrioventricular-Nodal Blocker & Drug Class \\
\hline Simmons and Blazar 2019 [2] & Metoprolol & $\beta$-Blocker \\
\hline Ahmad and Tan 2017 [3] & Amlodipine, bisoprolol & Calcium-channel blocker, $\beta$-blocker \\
\hline Juvet et al. 2013 [4] & Sotalol & Combine $\mathrm{K}^{+}$-channel and $\beta$-blocker \\
\hline \multirow{2}{*}{ Hegazi et al. 2012 [5] } & Verapamil & Calcium-channel blocker \\
\hline & Verapamil & Calcium-channel blocker \\
\hline \multirow{2}{*}{ Aziz et al. 2011 [6] } & Amlodipine & Calcium-channel blocker \\
\hline & Carvedilol & Non-selective $\beta$-blockers \\
\hline Erden et al. 2010 [7] & Carvedilol & Non-selective $\beta$-blockers \\
\hline Argulian 2009 [8] & Amlodipine, metoprolol & Calcium-channel blocker, $\beta$-blocker \\
\hline
\end{tabular}

TABLE 2: Atrioventricular-nodal blockers that precipitated bradycardia, renal failure, atrioventricular nodal blocker, shock, and hyperkalemia syndrome in each case

In order to make a diagnosis of BRASH syndrome, the patient should have bradycardia in the setting of synergistic effect of hyperkalemia and history of use of AV-nodal blockers with underlying renal insufficiency secondary to any medical condition. Mostly, BRASH patients are on the usual chronic doses of 
chronotropic drugs and often do not have signs of a drug overdose. They are seen to be hyperkalemic and have a certain degree of renal insufficiency. AV-nodal blockers concomitant with hyperkalemia can cause any type of bradycardia ranging from junctional bradycardia to third-degree AV block. Patients with BRASH syndrome may present with severe symptomatic bradycardia with a mild elevation of potassium without any EKG findings of hyperkalemia. Most of the patients clinically respond to intravenous calcium $40 \mathrm{mg} / \mathrm{kg}$ and insulin with D50.

\section{Conclusions}

BRASH syndrome presents with severe hypotension and bradycardia in a setting of chronotropic drug use and renal failure. Patients should be evaluated comprehensively for possible risk factors for hyperkalemia. The initial treatment should be directed toward improving the potassium levels and correcting the volume status. In refractory cases, catecholamines and a pacemaker may be needed to improve the hemodynamic status; however, the ACLS algorithm is not effective in managing these cases. Clinicians should take a careful approach when prescribing AV-nodal blockers in patients with multiple comorbidities and underlying kidney dysfunction.

\section{Additional Information \\ Disclosures}

Human subjects: Consent was obtained by all participants in this study. Conflicts of interest: In compliance with the ICMJE uniform disclosure form, all authors declare the following: Payment/services info: All authors have declared that no financial support was received from any organization for the submitted work. Financial relationships: All authors have declared that they have no financial relationships at present or within the previous three years with any organizations that might have an interest in the submitted work. Other relationships: All authors have declared that there are no other relationships or activities that could appear to have influenced the submitted work.

\section{References}

1. PulmCrit. BRASH syndrome: bradycardia, renal failure, AV blocker, shock, hyperkalaemia . (2016). Accessed: February 15, 2020: https://emcrit.org/pulmcrit/brash-syndrome-bradycardia-renal-failure-av-blockershock-hyperkalemia/.

2. Simmons T, Blazar E: Synergistic bradycardia from beta blockers, hyperkalemia, and renal failure. J Emerg Med. 2019, 57:41-44. 10.1016/j.jemermed.2019.03.039

3. Ahmad NH, Tan TL: Correlation of iatrogenic mild hyperkalaemia and bradyarrhythmia: a problem of polypharmacy in elderly. Med Health-Kuala Lumpur. 2017, 12:329-334. 10.17576/MH.2017.1202.17

4. Juvet T, Gourineni VC, Ravi S, Zarich SW: Life-threatening hyperkalemia: a potentially lethal drug combination. Conn Med. 2013, 77:491-493.

5. Hegazi MO, Aldabie G, Al-Mutairi S, El Sayed A: Junctional bradycardia with verapamil in renal failure-care required even with mild hyperkalaemia. J Clin Pharm Ther. 2012, 37:726-728. 10.1111/j.13652710.2012.01352.X

6. Aziz EF, Javed F, Korniyenko A, et al.: Mild hyperkalemia and low eGFR a tedious recipe for cardiac disaster in the elderly: an unusual reversible cause of syncope and heart block. Heart Int. 2011, 6:12.

7. Erden I, Yalcin S, Ozhan H: Syncope caused by hyperkalemia during use of a combined therapy with the angiotensin-converting enzyme inhibitor and spironolactone. Kardiol Pol. 2010, 68:1043-1045.

8. Argulian E: An unusual case of syncope. Am J Med. 2009, 122:636-638. 10.1016/j.amjmed.2009.03.017

9. Arnsdorf MF, Schreiner E, Gambetta M, Friedlander I, Childers RW: Electrophysiological changes in the canine atrium and ventricle during progressive hyperkalaemia: electrocardiographical correlates and the in vivo validation of in vitro predictions. Cardiovasc Res. 1977, 11:409-418. 10.1093/cvr/11.5.409

10. Montague BT, Ouellette JR, Buller GK: Retrospective review of the frequency of ECG changes in hyperkalemia. Clin J Am Soc Nephrol. 2008, 3:324-330. 10.2215/CJN.04611007 